language problems is likely to be a major obstacle if supplementation is given as tablets.

\section{References}

1 Whitehead $M$, Lane $\mathrm{G}$, Young $\mathrm{O}$, et al. Interrelation of calcium regulating hormones during pregnancy. $\mathrm{Br}$ Med $\mathcal{f} 1981 ; 283$ :10-2

${ }^{2}$ Krishnamachari K, Iyengar L. Effect of maternal malnutrition on the bone density of the neonate. Am F Clin Nutr 1975;28:482-6.

${ }^{3}$ Brook OG, Brown IRF, Bone CDM, et al. Vitamin D supplements in pregnant Asian women: effects on calcium state and fetal growth. Br Med 7 1980;280:751-4.

${ }^{4}$ Heckmatt JZ, Peacock M, Davies AEJ, et al. Plasma 25-hydroxy-vitamin $\mathrm{D}$ in pregnant Asian women and their babies. Lancet 1979;ii:546-9.

${ }^{6}$ Cameron JR, Sorenson J. Measurement of bone mineral in vivo: an improved method. Science 1963;142:230-2.

${ }^{6}$ Minton SD, Steichen JJ, Tsang RC. Bone mineral content in term and preterm appropriate for gestational age infants. $\mathcal{F}$ Pediatr 1979;95: 1037-42.

7 Roberts CC, Chan GM, Folland D, et al. Adequate bone mineralisation in breast-fed infants. $\mathcal{F}$ Pediatr $1981 ; 99: 192-6$.

${ }^{8}$ Skinner RK, Willis MR. Serum 25-hydroxy-vitamin D assay. Evaluation of chromatographic and non-chromatographic procedures. Clin Chim Acta $1977 ; 80: 543-54$.
${ }^{9}$ Forfar JO. Normal and abnormal calcium, phosphorus and magnesium metabolism in the perinatal period. Clin Endocrinol Metab 1976;5: 123-48.

${ }^{10}$ Cundy T, Kanis JA. Calcium homoeostasis during pregnancy. $\mathrm{Br}$ Med $\mathcal{f}$ $1981 ; 283: 562-3$.

11 Department of Health and Social Security. Recommended intake of nutrients for the United Kingdom. London: HMSO, 1969. (Reports on Public Health and Medical Subjects. No 120.)

12 Watney PJM, Chance GW, Scott P, Thompson JM. Maternal factors in neonatal hypocalcaemia: a study in three ethnic groups. Br Med $\mathcal{F} 1971$ ii :432-6.

${ }^{13}$ Widdowson EM, Dickerson JWT. In: Comar CL, Bonner F, eds. Mineral metabolism. Vol 2. New York: Academic Press, 1964.

${ }^{14}$ Shenolikar IS. Absorption of dietary calcium in pregnancy. Am $\mathcal{F}$ Clin Nutr 1970;23:342-4.

${ }^{15}$ Heaney RP, Skillman TG. Calcium metabolism in normal human pregnancy. F Clin Endocrinol Metab $1971 ; 33: 661-70$.

16 Cushard WG, Creditor MA, Canterbury JM, Reiss E. Physiologic hyperparathyroidism in pregnancy. F Clin Endocrinol Metab 1972;34:767-71.

17 DeLuca HF. Some new concepts emanating from a study of the metabolism and function of vitamin D. Nutr Rev 1980;38:169-82.

18 Hillman LS, Haddad JG. Human perinatal vitamin D metabolism: 25 hydroxy-vitamin D in maternal and cord blood. $\mathcal{F}$ Pediatr $1974 ; 84: 742-9$.

\title{
Effect of environment on blood pressure: home versus hospital
}

\author{
M A YOUNG, D B ROWLANDS, T J STALLARD, R D S WATSON, W A LITTLER
}

\begin{abstract}
The effect of environment on blood pressure was studied by recording intra-arterial pressure continuously in nine patients with essential hypertension during controlled periods of activity and rest at home and in hospital. Mean systolic pressure was higher at home $(152 \pm 16 \mathrm{~mm} \mathrm{Hg})$ than in hospital $(138 \pm 11 \mathrm{~mm} \mathrm{Hg}$, $p<0.01)$, the difference being greatest during the period of activity (165 $21 v 142 \pm 13 \mathrm{~mm} \mathrm{Hg}, p<0.001)$; heart rates and diastolic pressures did not differ significantly at these times. Systolic pressure recorded by conventional sphygmomanometry was also higher at home $(173 \pm 23 v$ $159.23 \mathrm{~mm} \mathrm{Hg}, \mathrm{p}<0.01)$, as was diastolic pressure (98 10 v $89+11 \mathrm{~mm} \mathrm{Hg}, \mathbf{p}<0.02)$.

Systolic pressure was consistently higher at home, and this effect was independent of the presence of an observer. This must be taken into consideration when assessing blood pressure and efficacy of treatment in hospital.
\end{abstract}

\section{Introduction}

The decision to initiate lifelong treatment in a hypertensive patient is usually made in hospital, a hospital outpatient clinic, or a general practitioner's surgery. How well each of these environments reflects a patient's day to day blood pressure, however, remains speculative. To gain an idea of the true day to day pressure it is necessary to observe the patient in as

\footnotetext{
Department of Cardiovascular Medicine, East Birmingham Hospital and University of Birmingham

M A YOUNG, MRCP, honorary registrar

D B ROWLANDS, MRCP, honorary registrar

T J STALLARD, AIMLT, senior scientific officer

R D S WATSON, MD, MRCP, senior registrar

W A LITTLER, MD, FRCP, professor

Correspondence to: Dr M A Young.
}

many environments as possible, and it is also necessary to standardise those factors that affect moment to moment changes in blood pressure. ${ }^{1}$ Furthermore, the influence of observer interaction has been emphasised in the past, at times raising systolic pressure by as much as $45 \mathrm{~mm} \mathrm{Hg} .{ }^{2}$ We therefore designed this study to clarify the effects of the home and hospital environments on blood pressure during strictly controlled conditions of activity and rest and in the presence and absence of an observer.

\section{Patients and methods}

We studied nine patients (six men) aged 22-62 (mean age 45) diagnosed as having essential hypertension on the basis of three separate outpatient standard cuff pressures of at least $140 / 90 \mathrm{~mm} \mathrm{Hg}$. Korotkoff phase $\mathrm{V}$ was taken as diastolic pressure. Patients had no evidence of target organ damage, and secondary hypertension was excluded by clinical examination, estimation of urea, electrolyte, and creatinine concentrations, and intravenous pyelography when appropriate. Patients were untreated for at least three months before admission, and all gave informed consent.

Outpatient pressures were measured using a standard mercury sphygmomanometer; patients generally rested supine for about five minutes before their pressures were measured. After admission to hospital in the afternoon each patient was randomised to spend the first of the next two days either at home or in hospital. Five patients were randomised to spend the first day at home (mean age of group 44.6 years; three men; mean outpatient pressure 161/ $95 \mathrm{~mm} \mathrm{Hg}$ ) and four to spend the first day in hospital (mean age of group 44.7 years; three men; mean outpatient pressure $165 / 92 \mathrm{~mm} \mathrm{Hg}$ ). The following morning a Teflon cannula $1 \mathrm{~mm}$ in diameter was introduced percutaneously into the left brachial artery and intraarterial blood pressure recorded continuously on to a portable analogue recorder. ${ }^{3}$ The tape was analysed beat to beat by computer after periods of damping or artefact had been excluded. ${ }^{4}$

After cannulation at $9 \mathrm{am}$ patients were allowed to settle and familiarise themselves with wearing the equipment; they were also given diary cards to record their activities. At 11 am, depending on randomisation, the patient either was driven home or remained in hospital. Between 12 noon and 1 pm patients were told to have lunch. They were instructed to rest supine from $1 \mathrm{pm}$ to $2 \mathrm{pm}$ and 
to be active from $2 \mathrm{pm}$ to $330 \mathrm{pm}$. In the hospital this entailed walking up and down stairs and along corridors within the building, and also walking in the hospital grounds; at home patients were told to be active within the house and confines of their gardens. At $330 \mathrm{pm}$ patients again rested supine, and at $345 \mathrm{pm}$ cuff pressures were measured on three occasions using a Hawksley random zero sphygmomanometer. All indirect readings were made by the same observer (MAY) both at home and in hospital.

At $4 \mathrm{pm}$, with the recording period finished, the patient was either driven back to hospital or, if already in hospital, allowed unrestricted activity. The following day the reverse procedure occurred for each patient depending on the first day's randomisation.

Results were analysed using Student's paired $t$ test and analysis of variance.

\section{Results}

The figure shows the results. Throughout the period that was compared, between 12 noon and $4 \mathrm{pm}$, mean intra-arterial systolic pressure was significantly higher at home $(153+16 \mathrm{~mm} \mathrm{Hg} v 138$ $11 \mathrm{~mm} \mathrm{Hg}, \mathrm{p}<0.01$ ). The difference in systolic pressure was greatest during the period of activity $(165 \pm 21 v 142 \pm 13 \mathrm{~mm} \mathrm{Hg}, \mathrm{p}<0.001)$ but was also present during the second part of the rest period $(140 \pm 15 v 127 \pm 12 \mathrm{~mm} \mathrm{Hg}, \mathrm{p}<0 \cdot 05)$. There were no significant differences between heart rates $(82 \pm 15 v 79 \div 14$ beats $/ \mathrm{min})$ and diastolic pressures $(89+10 v 84 \pm 11 \mathrm{~mm} \mathrm{Hg})$ during the period of activity or during the rest period $(73 \pm 14 v 75: 14$ beats/min and $74+10 v 75+12 \mathrm{~mm} \mathrm{Hg}$ respectively). Analysis of variance confirmed the significantly higher systolic pressure at home $(p<0.001)$ and showed that the effects of activity were similar at home and in hospital.

Indirectly measured systolic pressure confirmed the results obtained by direct intra-arterial recording, systolic cuff pressure being significantly higher at home $(173+23 v 159+23 \mathrm{~mm} \mathrm{Hg}, \mathrm{p}<0 \cdot 01)$; diastolic cuff pressure, however, was also higher at home $(98 \pm 10 v$ $89 \pm 11 \mathrm{~mm} \mathrm{Hg}, \mathrm{p}<0 \cdot 02$ ). Outpatient cuff pressures were similar to those measured after at least 24 hours' acclimatisation in hospital $(163 / 93 v 159 / 89 \mathrm{~mm} \mathrm{Hg})$, although conditions in the outpatient clinic were not as well controlled as those during the study period and the attending physician varied.

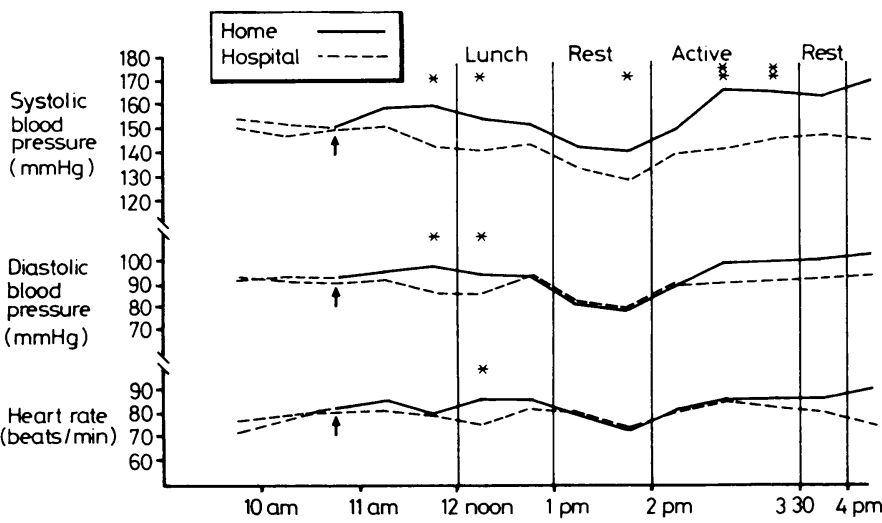

Mean intra-arterial systolic and diastolic pressures and heart rates in the two environments. Arrow indicates when patients left hospital for home. ${ }^{*} \mathrm{p}<0.05 .{ }^{* *} \mathrm{p}<0.001$.

\section{Discussion}

Most previous studies of blood pressure in different environments have compared home and clinic pressures and have usually shown lower pressures at home, ${ }^{5-8}$ although a large range of differences has been observed between clinic and home observations. ${ }^{8}$ Julius et al found $30 \%$ of patients with borderline hypertension in the clinic to be hypertensive at home. ${ }^{6}$ Observer effect inevitably played a part in these studies, as home recordings were taken by the patient and clinic recordings by the physician. Moreover, because of the nature of the recording methods a true reflection of the patients' range of pressures during activity could not be obtained. Studies comparing blood pressure in the outpatient clinic and in hospital have usually shown the "hospitalisation effect" " after a variable period of time ${ }^{910}$; similar problems again existed in these studies.

In this study we tried to allow for these factors by using $\frac{3}{\mathbb{D}}$ intra-arterial ambulatory recording, which removes the ob- $\frac{\varrho}{c}$ server and allows blood pressure to be measured during activity as well as rest. We found that direct arterial pressure was $\varrho$ significantly higher at home compared with in hospital, the greatest difference being $23 \mathrm{~mm} \mathrm{Hg}$ during the periods of $\mathbb{D}$ activity. The most obvious explanation for this would seem to be a greater degree of activity in the home; heart rates, however, 으. were not significantly different between each environment $\vec{\Rightarrow}$ during the period of activity and, furthermore, the difference in $\stackrel{5}{\rightarrow}$ systolic pressure was also present during the rest period. Both $\bar{c}$ these observations indicate that increased activity, at least by $\frac{\bar{F}}{\bar{m}}$ itself, was not the cause of the higher pressures at home, and $\overline{\bar{D}}$ indeed the patients' diary cards showed no appreciable dif- $\mathbb{Q}$ ferences in activity between the two environments. It might be argued that being at home with an intra-arterial line in situ is a stressful experience and may thus increase blood pressure; wearing the same equipment on a busy cardiology ward, how- $\vec{\omega}$ ever, would probably lead to a similar degree of "stress." The $\stackrel{\mathscr{\omega}}{\circ}$ presence of members of the family may conceivably affect $\frac{\partial}{3}$ blood pressure in the home, and all patients had at least one member of the family in the house during the home recording $\infty$ period, although only one had young children present. Although of conceivably increasing stress, family members would 'also be likely to reduce the patients' need to be active-that is, having an opposite effect.

The home environment may possibly have been colder than of the ward, where the average temperature was $23^{\circ} \mathrm{C}$. A recent $\frac{\mathrm{O}}{\mathrm{O}}$ report indicated that variations in air temperature of $20 \mathrm{C} \overrightarrow{\vec{D}}$ may alter blood pressure by $2-7 \mathrm{~mm} \mathrm{Hg}$ systolic and $2-4 \mathrm{~mm} \mathrm{Hg}$ diastolic pressure." It is unlikely, however, that this was an important influence in our patients since the temperature difference between hospital and a comfortably warm house $\vec{\varnothing}$ could have had only a very small effect on blood pressure.

In conclusion, we believe that our findings must be taken $\varnothing$ into consideration when assessing control of blood pressure and efficacy of treatment regimens in hospital.

We thank Miss A M Strong for preparing the manuscript and $\frac{\mathscr{D}}{\varnothing}$

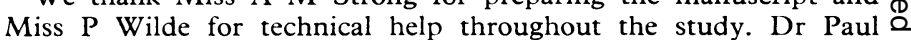
Davies kindly provided statistical advice and performed the analysis $\overrightarrow{\overrightarrow{0}}$ of variance.

\section{References}

Watson RDS, Stallard TJ, Flinn RM, Littler WA. Factors determining direct arterial pressure and its variability in man. Hypertension 1980; 2:334-41

2 Richardson DW, Honour AJ, Fenton GW, Stott FH, Pickering GW. Variation in arterial pressure throughout the day and night. Clin Sci $ᄋ$ $1964 ; 26: 445-60$.

${ }^{3}$ Littler WA, Honour AJ, Sleight P, Stott FD. Continuous recording of direct arterial pressure and electrocardiogram in unrestricted man. Br Med J 1972 ;iii:76-8.

-Watson RDS, Stallard TJ, Littler WA. Influence of once daily ad- O ministration of $\beta$-adrenoreceptor antagonists on arterial pressure and $\frac{D}{O}$ its variability. Lancet $1979 ; \mathrm{i}: 1210-3$.

- Ayman D, Goldshine AD. Blood pressure determinations in patients with $\mathrm{N}$ essential hypertension. Am f Med Sci 1940;200:465-77.

${ }^{6}$ Julius S, Ellis CN, Pascual AV, et al. Home blood pressure determination: value in borderline (labile) hypertension. F $A M A$ 1974;229:663-6.

Sokolow M, Perloff D, Cowan R. Contribution of ambulatory blood pressure to the assessment of patients with mild to moderate elevation of office blood pressure. Cardiovascular Reviews and Reports 1980;1: 295-303.

"Laughlin KD, Sherrard DJ, Fisher L. Comparison of clinic and home blood pressure levels in essential hypertension and variables associated $O$ with clinic-home differences. F Chronic Dis 1980;33:197-206.

${ }^{9}$ Hossmann V, FitzGerald GA, Dollery CT. Influence of hospitalisation $\frac{\Upsilon}{\square}$ and placebo therapy on blood pressure and sympathetic function in essential hypertension. Hypertension $1981 ; 3: 113-8$.

10 Hecht K, Hecht T, Trepton K. Bezienhungen zwischen Funktionszustand des ZNS und dem konditionierten pharmakologischen Effekt. Actå Biol Med Ger 1968;20:773.

"Brennan PJ, Greenberg G, Miall WE, Thompson SG. Seasonal variation in arterial blood pressure. $\mathrm{Br} \mathrm{Med} \mathcal{F}$ 1982;285:919-23.

(Accepted 2 March 1983) 